\title{
El cine de la "primera línea de resistencia» como fuente para la historia: FUS en huelga
}

\author{
Clara Perugorría y Jazmina Suárez'
}

Recibido: 21/4/2020; Aceptado: 29/6/2020

DOI: https://doi.org/10.37125/ISR.7.1.8

\section{Resumen}

El objetivo principal de este artículo es reflexionar acerca de los archivos audiovisuales como fuentes para la Historia en el marco de nuestra participación como estudiantes en el Espacio de Formación Integral (EFI) «Los trabajadores y la historia» durante el año 2019. La propuesta inicial de los docentes a cargo del EFI fue vincularnos a la Federación Uruguaya de la Salud (FUs) a través del acercamiento a un conflicto sindical específico: la huelga de la salud de 1985. Para ello, conformamos un grupo de estudiantes interesados en analizar la película Fus en huelga. La salud junto al pueblo, de Grupo Hacedor (1985), y lo complementamos con dos entrevistas a personas vinculadas a la producción de la película y al movimiento sindical. En el trabajo se consideraron las discusiones acerca del cine documental para clasificar el film, para después pasar a su análisis estético-narrativo. Además, el trabajo nos permitió reflexionar acerca de la historia oral, y la historia y memoria sindical, así como la importancia de la integralidad para la historia de los y las trabajadoras. Con nuestro trabajo pretendemos examinar una fuente histórica novedosa, intercambiar conocimientos con quienes participaron del conflicto de diferentes formas e incitar a incluir este tipo de documentos a la historia sindical. Pero no solo, ya que consideramos que la película ofrece múltiples posibilidades para la historia y otras disciplinas ya que constituye un registro único de la primera huelga de trabajadores posdictadura y expresa a través de un medio audiovisual gran parte del contexto de época.

Palabras clave: historia del cine, historia de género, historia del movimiento obrero.

\section{Introducción}

En 2019, como parte de nuestra formación como historiadoras, nos incorporamos al EFI Los trabajadores y la historia. El presente artículo surge como una forma de dar cuenta de la experiencia en el mencionado espacio. A partir de un acercamiento inicial, decidimos continuar ahondando en nuestro trabajo dándole mayor contenido y fundamento. El EFI, que tiene ya varios años, se ha enfocado en la vinculación y el

1 Licenciatura en Historia, Facultad de Humanidades y Ciencias de la Educación, Universidad de la República. jazminasuarez142@gmail.com, clara.p1312@gmail.com. 
trabajo en conjunto entre estudiantes y sindicatos. Al igual que el año anterior, en 2019 el vínculo fue con trabajadores de la Federación Uruguaya de la Salud (FUs). Los docentes e investigadores a cargo del EFI, Nicolás Duffau, Pablo Ferreira y Sabrina Álvarez, plantearon la tarea de acercarnos a la historia de la huelga de 1985, la primera después de recuperada la democracia, a través del trabajo con dos tipos de fuentes: prensa escrita y un audiovisual. Luego de varios talleres sobre historia del movimiento sindical en Uruguay y de tipo metodológico brindados por los docentes, conformamos un grupo basado en el interés de estudiar el conflicto a través de la película - recientemente digitalizada - Fus en huelga. La salud junto al pueblo, producida por Grupo Hacedor (1985). De esta manera, desde nuestro rol como estudiantes, nos propusimos, por un lado, investigar el conflicto sindical y, por otro, reflexionar sobre FUs en huelga... como una posible fuente para incorporar a los estudios sobre historia reciente.

En 2015 la Fus publicó un libro que recoge la historia de sus cincuenta años de existencia (1965-2015). Este libro (Federación Uruguaya de la Salud [FUs], 2015) constituye un gran aporte, surgido como iniciativa del propio sindicato, para acercarnos a la historia de un gremio relevante en la historia nacional. Sin embargo, el conflicto que en esta oportunidad abordamos no está recogido en sus páginas. La Fus se constituyó en el año 1965 como la unificación de los trabajadores de la salud privada, con una estructura federativa que intentó abarcar todo el territorio nacional. La iniciativa surge en un contexto de gran impulso en torno a la unificación sindical: en 1965 se lleva a cabo el Congreso del Pueblo y en 1966 la definitiva constitución de la Convención Nacional de Trabajadores que hace suyo el programa de aquel. Sin embargo, el proceso de unificación de los gremios de la salud fue complejo y tuvo diferentes ritmos en el territorio nacional (FUS, 2015, p. 27). A partir de su fundación, el gremio logró, a través del empleo de medidas sindicales, importantes conquistas que mejoraron significativamente las condiciones laborales de los trabajadores administrativos, de enfermería y servicios. Por ejemplo, el reconocimiento de antigüedad, la reducción horaria y ampliación de licencias para los diversos sectores (FUS, 2015, pp. 36-37).

Para nuestro trabajo decidimos complementar la fuente audiovisual con testimonios orales por dos motivos: el primero tiene que ver con el hecho de que es un archivo fílmico rescatado recientemente y, por lo tanto, no fue incluido en la bibliografía sobre el período histórico que abordamos; además, hasta el momento no se han producido estudios historiográficos sobre Grupo Hacedor. En segundo lugar, nos interesa reflexionar sobre los archivos fílmicos como fuente para la Historia. Para ello, la historia oral nos permite acercarnos a la relación de los individuos con su historia porque revela lo que la gente hizo, lo que deseaba hacer y lo que creyeron estar haciendo. En este sentido, decidimos entrevistar a un integrante de Grupo Hacedor: Eduardo Saraiva, ${ }^{2}$ y a un miembro del sindicato de la salud en el momento de la

2 Entrevistado por Enrique López, Clara Perugorría y Jazmina Suárez, en Montevideo, el 28 de octubre de 2019. 
huelga y que también posee una trayectoria vinculada con los medios audiovisuales: José Pedro Charlo. ${ }^{3}$

\section{Nuevas fuentes, nuevos temas y formas de investigación}

A partir de la segunda mitad del siglo xx se produjo una renovación en el campo de la historiografía. Los nuevos temas de interés, que progresivamente dejaron de lado la historia de los grandes personajes, ocasionaron nuevos desarrollos teórico-metodológicos, incorporando nuevas fuentes para la investigación antes no tenidas en cuenta. Entre ellas se encuentran las producciones audiovisuales y las fuentes orales. Ambos tipos de fuentes muestran elementos del pasado que no se pueden apreciar en las fuentes tradicionales: la vida cotidiana, los sectores subalternos, entre otros.

Como parte de las actividades de formación, la y los docentes encargados del EFI propusieron un taller de formación sobre la historia de la Fus ofrecido por un militante de la Federación: Pablo Anzalone. Esta instancia propició el intercambio entre estudiantes y el mencionado representante de la Fus, quien intentó reconstruir la historia de su sindicato desde sus conocimientos y experiencias. En este sentido, es significativo el involucramiento y la preocupación de los miembros y exmiembros de la Fus en conservar, recuperar y compartir la historia del sindicato con el resto de la sociedad. Sin esta conciencia, no hubiese existido la película que en esta oportunidad analizamos. Además, como mencionamos antes, la Federación cuenta con un libro editado que recorre la historia de la Fus. Como estudiantes de Historia, estos elementos nos despertaron reflexiones en torno a las posibilidades de los sindicatos, y en un plano más general de los sectores subalternos, de reconstruir su propia historia. Para lo cual, uno de los caminos puede ser el de la extensión universitaria: "proceso educativo transformador donde no hay roles estereotipados de educador y educando, donde todos pueden aprender y enseñar» y que «contribuye a la producción de conocimiento nuevo, que vincula críticamente el saber académico con el saber popular» (Universidad de la República, Consejo Directivo Central, 2009).

En este intercambio con la Federación surgieron consideraciones en torno a la búsqueda de integridad ${ }^{4}$ en la relación entre los sujetos (estudiantes y trabajadores de la FUS) para lograr un intercambio efectivo de saberes y un reconocimiento recíproco. Como bien señala Gerardo Sarachu (2012), las estrategias desarrolladas en

3 Entrevistado por Nicolás Duffau, Enrique López, Clara Perugorría y Jazmina Suárez, en Montevideo, el 21 de octubre de 2019.

4 Sarachu concibe a la integralidad en tres niveles, uno de ellos, al que nos referimos, se relaciona a la «búsqueda de integridad o aquella cualidad de íntegro, en el sentido subjetivo de generar un vínculo entero y cabal que nos lleva a pensar en los desafíos ético-políticos y desarrollar el potencial reflexivo sobre nuestras acciones individuales y colectivas en tantos sujetos, al mismo tiempo sociales y únicos, indivisibles pero incompletos» (2012, pp. 15-16). Los otros dos sentidos adjudicados al concepto y práctica de integralidad por Sarachu son, por un lado, lo integral como aquello que contiene todas las partes de la cosa tratada, intentando superar las aproximaciones fragmentarias; por el otro lado, integralidad entendida como la noción de integrar, como aquella capacidad de unir o interconectar. 
el EFI para una coproducción de conocimientos basada en el principio de igualdad parten del vínculo íntegro y las confianzas construidas con los sujetos individuales y colectivos. Esto es esencial para superar la «unilateralización de los procesos de conocimiento, su carácter parcial y fragmentario, negador del sujeto cognoscente que predominan en el hacer universitario» (Sarachu, 2012, p. 16). Concebimos, entonces, la integralidad como un espacio para la experimentación de formas de investigación que tenga en presente el potencial creativo de los sujetos participantes. Por otra parte, nuestra experiencia se enmarca en la metodología participativa de la ecología de saberes que tiene como objetivo combatir la injusticia cognitiva, romper con la lógica de consumo de información, con el fin de coparticipar en investigaciones con organizaciones sociales (Sarachu, 2012). Esto tiene como consecuencia pensar el saber como una construcción colectiva, en nuestro caso entre estudiantes y la Fus. Pero también, la necesidad de transformar la tradicional relación sujeto-objeto en el análisis histórico para construir una relación sujeto-sujeto, en el que estudiantes y trabajadores de la salud abordan de manera conjunta el objeto de estudio. Con todas estas ideas en mente fue que nos lanzamos a una recuperación crítica de la historia reciente, en la que privilegiamos la memoria colectiva (no solo de la FUs, sino también de Grupo Hacedor) y el rescate del primer ciclo de lucha y protesta posdictadura. La introducción de la integralidad en la investigación histórica trae aparejada nuevas temáticas, nuevos enfoques, nuevas fuentes, nuevas interrogantes y nuevas respuestas.

Sobre las fuentes orales podemos decir que no son objetivas - ninguna fuente lo es-, son artificiales, variables y parciales, puesto que el contenido de estas depende en gran medida de las preguntas e hipótesis que realice el investigador. Siguiendo a Dora Schwarzstein (2001, pp. 13-35), es la manera en que son interpretadas y analizadas lo que le da una significación determinada a este tipo de fuentes.

En las entrevistas, algunos de los desafíos que tuvimos que enfrentar fueron las omisiones inconscientes y distorsiones propias de la mente humana y del paso del tiempo. Además, somos conscientes de la escasa representatividad de nuestras fuentes orales. Como se ha mencionado anteriormente entrevistamos solo a dos personas: Eduardo Saraiva, que pertenecía a Grupo Hacedor (GH) en el momento de la filmación de fus en huelga..., y a José Pedro Charlo - quien se incorporó en la década de 1990 al Grupo-, pero participó del conflicto como trabajador del Círculo Católico al momento de la huelga. Consideramos que los aportes de otros integrantes de GH podrían sumar ampliamente a la reflexión, por diversos motivos no contamos con sus relatos, pero no los descartamos para futuras investigaciones. De esta manera, Eduardo Saraiva con su testimonio se convierte en una suerte de portador oficial de la historia de GH, lo que, sin dudas, debemos cuestionar permanentemente. Teniendo en cuenta todos estos aspectos que hacen a la historia oral, creemos que para este trabajo es un elemento ineludible y enriquecedor, ya que revela más sobre el significado de los hechos que sobre los hechos mismos. 
Por otra parte, el cine ha sido incluido en la historiografía como una fuente en las décadas de 1970 y 1980, cuando aparecen los primeros escritos de los que hoy en día se consideran "pioneros» en el tema: Marc Ferro y Pierre Sorlin en la historiografía francesa y Paul Smith, Anthony Aldgate, entre otros, en la escuela de Oxford (Alvira, 2011).

\section{El cine en la dictadura}

El movimiento de cine militante que caracterizó la década del sesenta terminó, producto de la persecución, censura y exilio, con la instalación del régimen militar en el país. Como parte de su proyecto cultural, el gobierno de facto tuvo una gran preocupación por los medios audiovisuales de comunicación. Estas iniciativas estaban dirigidas hacia la población nacional en busca de adhesiones, pero también hacia al exterior, tratando de mejorar su imagen internacional (Secco, 2018, p. 65). En 1975, llamado por el gobierno «Año de la Orientalidad», las autoridades crearon la Dirección Nacional de Relaciones Públicas (DINARP) con el fin de que este organismo desarrollara tareas de propaganda, censura y fomento de la actividad audiovisual. El régimen intentó impulsar un nuevo cine nacional, lo cual incentivó el desarrollo de informativos para cine: Panorama y Uruguay hoy, documentales y una sola película de ficción: Gurí. El gobierno militar sostuvo una guerra contra todo aquello que consideró subversivo, en este contexto, la cultura fue un campo más de batalla. Los militares desarrollaron, o al menos lo intentaron, un proyecto cultural que, según Aldo Marchesi (2009, p. 389), se fundó sobre tres pilares ideológicos: el pensamiento conservador tradicional, el neoliberalismo y la doctrina de la seguridad nacional.

El politólogo Luis Eduardo González planteó una periodificación de la dictadura (1973-1985) muy influyente y utilizada por diferentes historiadores que resulta práctica para abordar el tema, aunque no está exenta de observaciones. La primera fase que transcurrió entre 1973 y 1976 se denomina dictadura comisarial y fue cuando el gobierno de facto se enfocó en acabar con la subversión; la segunda es llamada ensayo fundacional, la cual llegó hasta el año 1980; la última es la transición democrática que concluyó con la asunción del gobierno por parte de autoridades elegidas democráticamente. Marchesi (2009, p. 330) destaca tres apuestas culturales desarrolladas por el gobierno militar en la segunda mitad de la década de 1970 - luego de la dura etapa comisarial, comenzó la fase fundacional del régimen-: exaltación patriótica a través de monumentos y celebraciones, la construcción de un sistema de medios de comunicación favorables al régimen y políticas dirigidas hacia la juventud enfocadas en la educación y el deporte.

Este programa cultural heterogéneo comenzó a trastabillar con la derrota plebiscitaria de 1980. La reorganización sindical y estudiantil, el surgimiento de diferentes movimientos sociales, la aparición de los partidos políticos; más la crisis económica que marcó el fin del período dictatorial y la disolución de alianzas económicas; 
cuestionaron elementos fundamentales del discurso castrista como la asociación entre dictadura, nacionalismo y cultura (Marchesi, 2009, p. 390). Además, hacia fines de la década de 1970 comenzaron a surgir propuestas culturales que no formaban parte del proyecto cultural dictatorial. Es el caso de diversos grupos musicales y el surgir del llamado canto popular, obras teatrales y literarias. Progresivamente, surgieron en diversos ámbitos y a través de diferentes medios (revistas, semanarios, programas de televisión, entre otros) nuevas expresiones culturales. Sin embargo, la censura continuó operando (Marchesi, 2009, p. 384).

Un espacio destacado entre las reducidas propuestas culturales durante el período dictatorial lo ocupa la Cinemateca Uruguaya, que para ese entonces ya contaba con décadas de funcionamiento en la capital del país. Estudios recientes de Germán Silveira recogen la historia del público de la Cinemateca Uruguaya. ${ }^{5}$ Uno de los puntos destacados en la investigación de Silveira, su tesis de doctorado, es este público durante la dictadura. En 1975 Cinemateca lanza su sistema de abonados. El abono mensual de libre acceso a todas las funciones era de dos mil pesos, es decir, el precio de dos entradas del circuito comercial (Silveira, 2015, p. 2). Estos aspectos resultaron en que, mientras que en las salas de estreno disminuía la cantidad de espectadores, las salas de Cinemateca revertían esta tendencia (Silveira, 2015, p. 3). Para Manuel Martínez Carril, director de la Cinemateca Uruguaya, y Henry Segura, editor de Cinemateca Revista, la propuesta no era de enfrentamiento o resistencia directa al régimen militar, sino que era una acción cultural que trascendía lo circunstancial y se planteaba «como la lucha por la liberación del mercado cultural ocupado por los intereses de las transnacionales» (Silveira, 2015, p. 4). Silveira recoge testimonios de las y los socios que concurrían a estas salas durante dictadura y el sentido que a esta actividad le atribuían. Este público contaba con un importante componente juvenil y estudiantil, que por un bajo costo podían acceder a cine de autor. Además, los testimonios hacen énfasis en la importancia de verse con personas en la cola antes de entrar a las salas: «tenían una verdadera función social, de encuentro» (Silveira, 2015, p. 6). En un momento en el que las posibilidades de reunión eran muy restringidas, Cinemateca fue un lugar de encuentro para esta generación en general y, en particular, para aquellas personas interesadas en la práctica cinematográfica y superochista. Esta actividad cultural permitió, al menos por unas horas, «escapar del encierro en el cual te querían hacer vivir» (Silveira, 2015, p. 9).

El proyecto cultural castrense (al igual que el económico y político), no logró generar fuertes y duraderas adhesiones entre los diferentes sectores de la sociedad. Los intentos disciplinadores que se impartieron desde la educación hacia los jóvenes fueron poco eficaces, y estos fueron importantes protagonistas dentro de los movimientos sociales antidictatoriales durante la transición democrática y luego de ella. Los jóvenes elaboraron diferentes propuestas culturales alternativas hacia el final del período dictatorial, Grupo Hacedor es una de ellas.

5 Véase Germán Silveira (2019). 


\section{La huelga: registro fílmico y recuerdo oral}

\section{Primera huelga posdictadura}

La huelga general de la salud fue declarada el día jueves 11 de julio de 1985 en una asamblea realizada en el Palacio Sudamérica. Desde ese momento los lugares de trabajo fueron ocupados y durante casi tres semanas funcionaron bajo control obrero [...]. Frente al tope de $22 \%$ que ofrecía el Poder Ejecutivo y las patronales, se reclama un aumento salarial mínimo del $30 \%$, ajustes bimensuales, seis horas de trabajo, categorías con salario mínimo, licencia, horas extras dobles, compensación nocturna, afiliación familiar gratuita, cese de represalias patronales, no a los descuentos por paro en La Española, ImPasa, Clínica Prado y Británico, reposición de todos los destituidos en Casa de Galicia, Universal y Médica Uruguaya (Grupo Hacedor, 1985).

La huelga de la Fus se desarrolló desde el 11 de julio de 1985, meses después de que asumiera el primer presidente elegido democráticamente luego de la dictadura, Julio María Sanguinetti. Las elecciones nacionales de 1984 contaron con aproximadamente cinco mil ciudadanos proscritos, dentro de los que se encontraba el dirigente nacionalista Wilson Ferreira Aldunate, y unos trescientos presos políticos. Al dirigente frenteamplista Líber Seregni no se le permitió la candidatura y a la coalición integrada por los sublemas Democracia Avanzada, Izquierda Democrática Independiente, Partido Socialista, Partido Demócrata Cristiano y la Lista 99 no se le habilitó el uso del lema Frente Amplio (Broquetas, 2008). Estas fueron algunas de las condiciones que fueron acordadas en el llamado Pacto del Club Naval y que marcaron el rumbo de las elecciones de noviembre de 1984.

El presidente electo ejerció su mandato en un contexto particular: las iniciales expectativas de la redemocratización del pueblo se enfrentaban a los sectores que detentaban el poder y sus nuevos planes de liberalización económica. Asimismo, debía enfrentar las consecuencias de la crisis de la tablita de 1982, producto de una fuga masiva de capitales por la que el país aumentó su endeudamiento externo. Esta situación produjo la interrupción de la intervención del Estado en el mercado de cambios causando una devaluación abrupta que triplicó el precio del dólar. En 1983, el gobierno de facto pactó con el Fondo Monetario Internacional. Para la población, esto se tradujo en un encarecimiento de los costos de vida (aumento del IVA y de las tarifas públicas). A todo esto, se le sumó la fuga de capitales extranjeros. Los sectores más afectados fueron los sectores productivos, asalariados y pasivos. Para 1985 se había heredado una deuda externa y un endeudamiento interno que impedía el crecimiento económico (Broquetas, 2008, pp. 191-200).

La participación del movimiento sindical en el retorno de la democracia fue clave. Desde 1981 los grupos opositores de la sociedad civil mantuvieron un grado de movilización importante que tuvo su punto máximo el 1. ${ }^{\circ}$ de mayo de 1983. Además, durante los últimos años de dictadura se gestaron nuevos movimientos sociales y reorganizaron otros que habían surgido en la etapa previa al golpe de Estado: derechos humanos, cooperativo, de mujeres y de ollas populares (Broquetas, 2008). Sobre el 
terrorismo de Estado, Grupo Hacedor produjo la película Los ojos en la nuca (1988). Esta se filmó desde 1983 a 1985 y constituye un compilado de testimonios que denuncia la situación de los presos y las torturas en centros clandestinos, los desaparecidos, los rehenes, así como imágenes de la asunción presidencial de 1985 y la liberación de los presos políticos.

Como bien nos relata la voz over de la película, la huelga de la salud condensa aspectos de la realidad política — reposición de destituidos, amnistía, aplicación de sanciones a los responsables de violaciones a los derechos humanos- y de la realidad económica del país y de las condiciones de vida de los trabajadores causadas por doce años de dictadura y la crisis económica de 1982. El conflicto, además, asumió un carácter especial por tratarse de una huelga de casi tres semanas con modalidad de control obrero de los lugares de trabajo. Este tipo de acción colectiva consistió en mantener el funcionamiento del lugar, es decir, los centros de salud siguieron funcionando, pero con la particularidad que la patronal ya no intervenía en la administración. En otras palabras, los obreros de la salud gestionaron los centros mientras duró el conflicto. Esto no es un detalle menor dado que se trata de un servicio de primera necesidad para la sociedad y el gobierno podría llegar a considerar esencial.

El control obrero de los centros asistenciales de la huelga de 1985 encuentra uno de sus precedentes según la FUS (2015, pp. 71-73) en el período de ascenso del autoritarismo, en la huelga de 1970. En ese entonces se desarrollaron hospitales populares para ganar la adhesión de la sociedad a las demandas de la Federación. Además de ocupar los centros, los huelguistas se dispusieron a ofrecer sin restricciones y de forma gratuita consultas y tickets de medicamentos (donde las patronales sacaban grandes ganancias) a todo aquel que lo solicitase. Uno de los propósitos era golpear fuertemente a la patronal que veía reducida su capacidad ahorro y estaba latente la posibilidad de que hubiera gastos, ya que se atendía sin restricciones y gratuitamente a toda la población. Una de las tácticas que emplearon los hospitales populares fue la de rotación, esto quiere decir que, para no sobrecargar a un centro de salud, iban rotando en su ubicación. Esta medida se llevó a cabo a pesar de que los 25 días de huelga supusieron la pérdida del salario de los trabajadores.

\section{Cine documental desde abajo}

De esta forma comienza la película FUS en huelga..., producida por Grupo Hacedor en 1985, la que podríamos clasificar como cine documental político. Si bien son exhaustivas las discusiones teóricas acerca de la naturaleza del cine documental, se ha llegado a un acuerdo en diferenciar los documentos como registros y el cine documental. Según Javier Campo (2015, p. 5) el cine documental es «aquel que hace uso de documentos audiovisuales para reconfigurarlos de acuerdo a parámetros estéticos cinematográficos que superen el grado de registro de la realidad». Es decir, las imágenes y sonidos no solo funcionan como un registro de lo real, sino que también se ordenan, modifican - temporal y espacialmente-, fragmentan y cambian 
los sucesos, elaborando discursos. En síntesis, la diferencia con los meros registros es la creatividad que aporta el documentarista como agente activo, que se interesa no por la transferencia de información, sino por el destino retórico (Campo, 2015, pp. 5-11).

Siguiendo a Campo (2015, p. 9), el discurso es «el conjunto de enunciados y narraciones documentales presentes en las obras». Esta organización de los materiales fílmicos no es azarosa, sino deliberada y pretende proyectar un modelo del mundo. A su vez, este autor sostiene - junto a varios otros- que una de las características del cine documental es ese acuerdo implícito a través del cual la comunidad de espectadores ve un documental como un documental, es decir, el modo en el que lo miramos. Es la meta de todo documental ser tomado como veraz.

Otra de las características que todos los estudiosos del cine documental le atribuyen tiene que ver con las funciones sociales que asume o, en última instancia, debería asumir. El documental surge para algunos autores como un medio para actuar en la sociedad como un soporte de determinadas políticas sociales y educativas (Campo, 2015, p. 13). Campo (2015) toma la idea de Johnatan Kahana al sostener que el cine documental al ser un tipo de discurso puede ser utilizado para diferentes fines ideológicos, puesto que es un medio de transición que lleva las imágenes de lo real a otro espacio que pueden ser utilizadas con múltiples fines. La articulación de los objetivos del documental con los de la sociedad es vista por varios estudiosos del cine como viable y necesaria dado que trata al espectador como parte activa de la sociedad. Antes dijimos que fus en huelga se trataba de un film documental político, siguiendo a Campo (2015) se puede decir que

De un rastreo no muy exhaustivo por la historia del cine documental surge como evidente el hecho de que el documental ha sido uno de los vehículos principales del discurso y la retórica política y que, por otra parte, un porcentaje significativo de los films documentales han presentado conceptos, problemáticas y posturas políticas de formas más o menos sutiles (p. 15).

Es decir, el documental tiene una tendencia a ser político ya que invita a la sociedad a observarse a sí misma y sus propias preocupaciones e invita al espectador a tomar un rol activo en tanto miembro de un colectivo.

A su vez, el cine documental político suele asociarse con el cine militante, que es la forma más extrema y tradicional de esta categoría. Sin embargo, Campo (2015, p. 18) advierte que el cine militante solamente adquiere esa denominación cuando circula como sostén de discusiones y acciones políticas. Como consecuencia de esto, el cine militante se acerca a la denominación de contrahegemónico ya que la circulación no será por los canales institucionales tradicionales. Por estas características descritas, FUs en huelga... no solo se acerca a la categoría de cine político, sino que también a la de cine militante dado que su circulación y única proyección (antes de ser digitalizada) se dio en la misma Federación. 
Sobre las características formales del documental político, Campo (2015, p. 19) resalta el carácter expositivo de los filmes que constantemente buscan argumentar con el propósito de convencer, dejando de lado la reflexión sobre las representaciones que produce. A su vez, este tipo de cine apoya esas representaciones en el hecho «dado» de existiría un vínculo entre lo real y lo que se muestra en el film. Es por esto que sobre el trabajo retórico se pone mucho empeño, debido a que necesita elaborar argumentos convincentes sobre el mundo para cambiarlo.

Grupo Hacedor es conformado hacia 1982 por Eduardo Saraiva, Hugo Videckis, provenientes de Cine Cooperativo (Cineco), Hugo Martínez y Wilfredo Camacho quienes se encontraban trabajando en Grupo Osib. Cineco emerge tras la disolución de la Cinemateca del Tercer Mundo - proceso que empezó hacia fines de 1971-y en la praxis funcionó como una cooperativa, aunque nunca se constituyó como tal. Tenían el objetivo de producir films para proyectarlos en escuelas y guarderías, lo que le da una característica familiar al grupo. Por sus bajos costos el proyecto utilizó paso ${ }^{6}$ Super 8 y su primera película fue Un honguito feliz (1976). Además, editaron e impulsaron la revista Fotocine, de elaboración rústica y artesanal que reunía, como su nombre lo expresa, ambas disciplinas. A través de esta revista, Cineco ofrecía clases de Super 8, reflexionaba sobre el cine nacional y difundía fichas de películas. El grupo se mantuvo activo realizando películas infantiles y filmaciones de todo tipo de eventos hasta 1984 (Keldjian, 2012, p. 10). Actualmente, no contamos con información sobre el grupo Osib.

El primer proyecto como Grupo Hacedor fue el film La azotea, sobre el que manifiesta algunas de las limitaciones para estas actividades durante el período dictatorial: se filmó en el interior de una casa, ya que estaba prohibido filmar en exteriores. El Grupo Hacedor se mantuvo activo hasta 1988, año en que se culmina Los ojos en la nuca y el grupo se disgrega.

En cuanto a FUs en huelga, es parte de un conjunto de películas de Grupo Hacedor que fueron elaboradas simultáneamente. Por este motivo, la obra puede verse como parte de un conjunto - Los ojos en la nuca (1988), $1 .^{\circ}$ de mayo de 1983 (1983) y FUS en huelga... (1985) - que posee la misma estética narrativa y visual y los mismos objetivos o, al menos, es lo que afirma Eduardo Saraiva en la entrevista realizada por el equipo (Saraiva, entrevista, 2019).

FUS en huelga fue producida en paso Super 8, muy difundido entre quienes practicaban el cine amateur, aunque, como señala Julieta Keldjian (2012, p. 6), en Uruguay estas clasificaciones son muy problemáticas debido a que en el país no hubo hasta la década de 1990 un campo cinematográfico profesional conformado. Por tanto, cine amateur y cine profesional no funcionan como categorías de análisis útiles para pensar este período. El soporte Super 8 fue lanzado en la década de 1960 por la empresa Kodak pensado para el uso doméstico. Lo que antes estaba restringido a una elite

6 Se denomina paso al tamaño de la película, compuesto por el ancho (expresado en milímetros) y al tipo de perforación (Del Amo, 2006, pp. 58-64). 
por su especialización y elevados costos se popularizó, la herramienta se hizo más liviana con lo que abrió otro marco de posibilidades y facilitó el acceso a la práctica cinematográfica a un público más amplio. Siguiendo a Keldjian (2012, p. 6), el Super 8 aparece como el soporte elegido para la expresión de una de las formas alternativas a la cultura hegemónica, conformándose así un movimiento de superochistas.

Para Keldjian (2012, p. 3), por su característica de cine a medio camino entre el cine mayor - de $35 \mathrm{~mm}$ - y el cine familiar, las películas filmadas en Super 8 fueron relegadas, como amateurs y marginales, del análisis de estudiosos del cine y de la crítica, prejuicio que perduró al momento de la conservación de ejemplares.

Un breve examen a las características técnicas del Super 8 nos permiten concluir que no solo se trataba de una elección estética-narrativa, sino que había más razones para su uso. Gracias al Super 8 se generalizó el uso de casetes, puesto que lograba simplificar su manejo tanto para el registro como para la posterior proyección de las películas (Keldjian 2012, p. 12). Esto es un dato muy relevante a la hora de analizar Fus en huelga puesto que, para el registro de asambleas, ferias vecinales, en transportes colectivos, en sanatorios y hogares residenciales se necesitaba practicidad y facilidad. A su vez, el soporte del Super 8 tenía un sistema reversible que consistía en convertir el negativo en positivo al lograr que el sistema de positivado se produzca sobre la misma película negativa; esto redujo considerablemente los costos de revelado, pero dificultó la obtención de copias por el costo económico que suponía el duplicado. Como consecuencia, las películas eran piezas únicas y de circulación muy limitada por su fragilidad (Keldjian, 2012, p. 12). En el caso de FUS en huelga, sostiene Saraiva (Entrevista, 2019), solo se exhibió «en la asamblea de la Fus, en ese mismo año [1985]. Esa fue la única exhibición que existió hasta no hace tanto que se recuperó y se digitalizó».

Según Keldjian (2012), la producción de este tipo de películas, que surgen como proyectos de tipo cooperativo, es muy particular. Los roles tradicionales de producción cinematográfica se desdibujan al compartir e intercambiar funciones. En el caso de Grupo Hacedor, era usual rotar en las tareas e incorporar a participantes fuera del grupo inicial (Saraiva, entrevista, 2019). Otra característica de esta forma alternativa de hacer cine eran las limitaciones económicas. En entrevista, Eduardo Saraiva (2019) recuerda la forma por la cual el grupo accedió a los rollos de película que les permitieron desarrollar sus proyectos: la empresa Kodak se iba del país y remataba sus últimos rollos de película vencidos. Grupo Hacedor obtuvo así 360 minutos de película que utilizaron para filmar $1^{\circ}$ de mayo 1983 (1983), FUs en huelga (1985) y Los ojos en la nuca (1988).

En cuanto al circuito de exhibición en Uruguay, Keldjian (2012, p. 5) afirma que, para este tipo de películas, surgidas de proyectos de tipo cooperativo y de contenido comprometido con la sociedad, era variado: fábricas, clubes sociales, institutos culturales y jardines de infantes y también, en algunas oportunidades, en festivales y concursos de Cine Arte del SODRE. 
La película dura $26 \mathrm{~m} 10 \mathrm{~s}$ y está filmada en formato Super 8. Según Saraiva (Entrevista, 2019) el film contaba con un preguión, esto dejaba abierta la posibilidad a lo espontáneo e imprevisto, lo cual refleja la concepción del grupo de realizadores de hacer un cine sobre la marcha. Para la producción, la Fus colaboró económicamente para la compra de materiales y orientó en materia sindical (locaciones, personas a entrevistar, las corrientes dentro de la Federación). No obstante, la ejecución desde la preproducción, pasando por la producción y la posproducción, corrió por cuenta de GH, por lo que tuvieron total libertad creativa. Para Grupo Hacedor (Saraiva, entrevista, 2019), con estos films se buscaba «... sacar una foto del momento para que en el futuro las generaciones las puedan ver y analizar. Ese era el origen del cine documental del Grupo Hacedor. Plasmar el momento y que el futuro vea otra perspectiva de la historia oficial».

Por otra parte, Grupo Hacedor concebía al cine documental desde una perspectiva desde abajo, es decir, descentrando el foco de atención de los dirigentes para concentrarse en las bases sindicales o populares. Saraiva (Entrevista, 2019) expresó esta visión al argumentar:

la idea era mostrar a los anónimos, creo que ese es el objetivo. Por eso creo que la gracia de un documento es que se prolongue en el tiempo, porque si vos hubieses hecho un panfleto con nombre y apellido estás haciendo algo que es combativo en su momento, pero que pierde carácter de documento histórico y eso es lo que intentamos hacer. Esa es la idea de Grupo Hacedor y lo que hizo.

Si bien lo más usual en los documentales es la voz over que narra desde el exterior, este tipo de cine se vale de más recursos para la argumentación retórica. La película comienza y finaliza con un cuadro oscuro y sonidos de fondo de sirenas de ambulancia. Saraiva (Entrevista, 2019) cuenta que fue un efecto buscado y logrado, ya que el sonido de las ambulancias es un símbolo de emergencia de la salud. El espectador puede interpretar que se trata de una situación de urgencia, signada por las condiciones laborales de los trabajadores y reminiscencias de la dictadura. Luego, se observan movilizaciones para recaudar fondos y propagandear el conflicto. En ellas se solicita ayuda y colaboración con peajes en la vía pública, en ómnibus y en ferias vecinales - Tristán Narvaja y Piedras Blancas-y así obtener recursos para el mantenimiento de la olla sindical de los funcionarios que ocupaban los centros de salud. Posteriormente, se muestran las condiciones laborales en el Hospital Italiano y en el residencial Lourdes. Después de la imagen de los titulares de órganos de prensa, se llega a la segunda asamblea en el Club Atenas, en la que, siguiendo el estilo de Hacedor, no se filman primeros planos, sino imágenes móviles. Se suceden dos asambleas más en las que se plantea el levantamiento del conflicto. En la tercera asamblea, convocada en el Palacio Peñarol, se acuerda el fin de la huelga, aunque el conflicto siguió en la Asociación Española y en el Hospital Italiano.

Por otro lado, Grupo Hacedor debía contemplar, al momento de filmar, la presencia de dos fuertes vertientes dentro de la fus: el Partido Comunista y La Tendencia. Esto 
requirió mantener un equilibrio en la filmación de ambas fuerzas. Refiriéndose a este aspecto, José Pedro Charlo (Entrevista, 2019) comenta que en el momento coexistían dentro de la fus dos corrientes: El Partido Comunista y lo que antes de la dictadura se denominó La Tendencia Combativa. En el momento de la huelga el Partido Comunista era la corriente mayoritaria en la FUS, mientras que del otro lado se agruparon personas vinculadas a grupos políticos como el Movimiento de Liberación Nacional-Tupamaros, Partido por la Victoria del Pueblo, Partido Socialista, e independientes. Mantener ese equilibrio mencionado por Saraiva (Entrevista, 2019) tiene como consecuencia dejar al desnudo que el cine documental construye un relato, en este caso, el equilibrio de dos corrientes en pugna. Si bien nos muestra que al final salió victoriosa una de las corrientes, a lo largo de la película se transmite que eran semejantes, que ninguna — solo hacia al final, con la asamblea que decide el levantamiento de la huelga - tenía mayor peso que la otra. Esto, como nos dijo Saraiva, tenía que ver con no mostrar preferencias por ninguna.

\section{Reflexiones finales}

A modo de síntesis, podemos referirnos a algunas contribuciones que esta película como fuente para la investigación histórica puede aportar. En primer lugar, nos acerca a la vida cotidiana de aquella época ya que el film registra a personas interactuando en un contexto específico: un ómnibus, una feria o una asamblea. En estos ámbitos se observan mujeres y varones con sus vestimentas y sus formas de hablar e intercambiar palabras, gestos y miradas. Todo lo cual se condensa en las concurridas asambleas donde se registran diferentes dinámicas, como la disposición en el espacio de las personas, la oratoria, la forma de votación, etcétera. Consideramos que la película ofrece estas posibilidades debido al lugar protagónico que se le asigna en la narración a los trabajadores de la salud - agremiados o no-, sus condiciones de trabajo, su entorno y sus formas de lucha. Esto sin omitir que los documentales son narrativas que reconfiguran los registros de la realidad.

El film también registra la significativa presencia de mujeres en el conflicto y esto se debe a que la salud fue y es un sector laboral altamente feminizado. Según Marcela Lagarde (2011, p. 409), las madres públicas son todas aquellas que a partir «de sus funciones, de sus actividades y de su trabajo, realizan la reproducción social en instituciones públicas». Entre ellas están las maestras, las médicas, las enfermeras, las cocineras, las trabajadoras sociales y secretarias, entre otras. Estas mujeres desempeñan funciones de reproducción que para ellas son trabajo y son reconocidas económicamente a través del salario y otras formas de pago. Cabe destacar que estos trabajos son considerados femeninos por ser reproductivos $y$, aun cuando ocurren en la esfera pública, son concebidos culturalmente como extensiones de la maternidad. Según esta autora feminista, estos trabajos son maternales porque 1) «ideológicamente estas actividades sociales se consideran servicios - de servir a un "otro"-» y 2) «estas mujeres tienen un estatuto social y jurídico de trabajadoras, por lo cual ocupan una 
posición subalterna en la sociedad de clases» (Lagarde, 2011, p. 410). Con toda la carga maternal que supone, la reproducción pública femenina es más visibilizada que la reproducción que hacen las mujeres en el ámbito privado — reciben un salario, tienen derechos y obligaciones-. Sin embargo, ese trabajo es realizado por mujeres trabajadoras y eso lo inferioriza doblemente; a esto se le suma que ocurre en la dimensión de sujeción laboral de clase. Para Lagarde (2011), la extensión pública de la maternidad, la feminización de estas actividades, y su doble inferiorización, se retroalimentan y terminan siendo pruebas de que las mujeres son aptas para hacerlos, creándose así un rol de género. Uruguay y el sector de la salud no fue, ni es, la excepción a este fenómeno: según la FUs (2015), actualmente el personal de la salud es femenino en un ochenta por ciento.

A nivel sindical, si bien la presencia de mujeres también es importante, históricamente los cargos más altos han sido ocupados por varones. Sin embargo, la ya mencionada perspectiva del documental, que hace foco en las bases sindicales, muestra la intensa movilización femenina que suscitó el conflicto.

Con todo, no debemos dejar de cuestionar nuestras las fuentes, ya sean las entrevistas realizadas para elaborar este artículo como la película en sí. El documental, por más pretensión de objetividad que posea - registrar la realidad «tal cual es»—es un producto de personas que, en el proceso de filmación y luego de edición, elaboran un discurso a través de ciertas imágenes registradas que luego atraviesan un proceso de selección. Es importante destacar que la historia, incluida la escrita, es una reconstrucción del pasado, no un reflejo directo. Cabría entonces preguntarnos: ¿qué y por qué se dejó fuera del producto final? Y, por otro lado, ¿cuánto posee de elaboración propia o posterior los planteos de nuestros entrevistados?

Siguiendo a Pablo Alvira (2011), lo difícil de la tarea es analizar qué y cómo se muestra, puesto que el cine incluye una multitud de elementos desconocidos para la historia escrita: condensaciones, síntesis, simbolizaciones con lenguaje propio que se ha transformado a lo largo de más de un siglo de existencia. Es menester no ver el cine como un vidrio transparente y tomar el relato como real y no como lo que es, una representación.

En conclusión, consideramos que FUs en huelga... es un material valioso como fuente para la historia y, concretamente, para la historia del movimiento sindical. En parte, porque en la historia del movimiento obrero los registros audiovisuales fueron postergados y solo recientemente se han empezado a incorporar al estudio de la temática. Es importante destacar que las y los trabajadores y sus luchas en Uruguay muy pocas veces han sido objeto de registros audiovisuales. Cuando lo han sido, fue en general por iniciativa de realizadores comprometidos socialmente como, por ejemplo, aquellos vinculados con el cine militante de los sesenta. Además, debido a la naturaleza del material fílmico y a la forma en que estos fueron conservados, el conocimiento, acceso, conservación y, por último, divulgación es un proceso, cuanto menos, intrincado. Por todo esto, no muchas huelgas fueron objeto de un film documental en Uruguay y 
en el caso de las que sí lo fueron, el acceso a las películas a través de la digitalización, por tanto, su inclusión y reflexión en los estudios históricos, ha sido tardío. En este sentido, podemos destacar otro aporte que Grupo Hacedor ha hecho al documentar el acto del Primero de Mayo de 1983, primera celebración con acto público y multitudinario del Día Internacional de los Trabajadores luego de ser prohibido durante diez años por el régimen civil militar. Según Julieta Keldjian y Beatriz Tadeo (2015, p. 90), la película, llamada $1 .^{\circ}$ de Mayo 1983, fue elegida para su digitalización y preservación en un proyecto junto con El honguito feliz de Cineco en el que trabajaron en conjunto la Universidad Católica del Uruguay, la Università di Udine de Italia y la University of Saint Andrews de Escocia. Este proceso de digitalización concluyó en copias de acceso en alta resolución y masters digitales de preservación de ambas películas. Otro aspecto, entonces, para pensar en las piezas audiovisuales como fuente para la Historia tiene que ver con el rol que juegan ciertas instituciones o personas en la preservación de este tipo de documentos.

La huelga de la salud marca un hito tanto en la historia nacional como en la sindical al ser la primera luego de finalizada la última dictadura. No obstante, es una huelga poco conocida que por sus dimensiones y repercusiones consideramos que debe ser rescatada del olvido y, de esta manera, poder contribuir a la historia y a la memoria del movimiento obrero uruguayo. En fin, la película nos invita a pensar en imágenes.

El entrevistado de Grupo Hacedor, Eduardo Saraiva, no esperaba nuestra entrevista, al menos no tan pronto. Esperaba que el interés por la obra del grupo surja mucho después y, sin eufemismos, cuando todos estén muertos. Pero no fue así. Trabajar con personas vivas es mucho más desafiante $y$, tal vez, más enriquecedor para nuestro presente. Quisimos intercambiar con los protagonistas de un hecho relativamente reciente y definitivamente relevante. Nos encontramos con que la huelga no fue recogida en un libro que recorre la historia de la fus y que la película era poco conocida. No ahondaremos en el porqué de esta omisión ya que no contamos con testimonios y documentos suficientes como para dar respuesta a esa interrogante. Esta experiencia nos convence de que el intercambio con agentes extrauniversitarios es fundamental para nuestra formación y futuro desarrollo profesional. No solo porque sean objeto de nuestros estudios, sino porque el trabajo desde la integralidad posibilita la reciprocidad y contribuye a la crítica ineludible de nuestros saberes.

Para nosotras, como futuras investigadoras, es fundamental repensar el rol del intelectual y abandonar ese lugar de olvido forzado de los sectores subalternos y que emprendamos el camino del reconocimiento de las condiciones objetivas y subjetivas de dominación. Coincidimos con Álvarez (2014) que para esto es necesario la construcción de los y las trabajadoras como colectivo, con la lupa puesta en sus condiciones vitales y laborales, con sus expectativas y sus opciones de consenso o resistencia ante la explotación. Esta construcción solo es posible concibiendo la Historia desde una perspectiva desde abajo, diferente y contraria a la Historia planteada desde el poder. Es sustancial para concretar esta tarea, introducirse en lo que 
son las prácticas de extensión universitaria, puesto que esta nos ayuda a repensar la relación objeto-sujeto y las fuentes que utiliza el conocimiento histórico, así como las metodologías y técnicas para su investigación.

\section{Referencias}

Álvarez, S. (2014). Dificultades, aportes y desafíos de la extensión universitaria para las Ciencias Históricas: algunas reflexiones. Revista Trama, 5(5), 99-108.

Alvira, P. (2011). El cine como fuente para la investigación histórica. Orígenes, actualidad y perspectivas. Revista Digital de la Escuela de Historia, 3(4), 135-152.

Broquetas, M. (2008). Liberación económica, dictadura y resistencia. 1965-1985. En A. Frega, A. M. Rodríguez, E. Ruiz, R. Porrini, A. Islas, D. Bonfanti, ... I. Cuadro, Historia del Uruguay en el siglo XX (1890-2005) (pp. 163-210). Montevideo: Ediciones de la Banda Oriental-Departamento de Historia del Uruguay, FHCE, Universidad de la República.

Campo, J. (2015). Cine documental: tratamiento creativo (y político) de la realidad. Cine documental, (11), $1-28$.

Del Amo, A. (2006). Clasificar para preservar. Madrid: Cineteca Nacional-Filmoteca Española.

Federación Uruguaya de la Salud (FUS) (2015). 1965-2015 Federación Uruguaya de la Salud Cinco décadas de lucha. Montevideo: Primero de Mayo.

* Grupo Hacedor (Productor). (1985). fus en huelga. La salud junto al pueblo [Película]. Uruguay: AGU, Universidad de la República. Recuperado de https://www.youtube.com/ watch?v=2VfHDZo9yP 4 \&t $=37$ s.

Keldjian, J. (2012). Superochistas. Dixit, (17), 4-12.

Keldjian, J., y TAdeO, B. (2015). ¿Digitalizar para preservar? Nuevas tecnologías para nuevos desafíos. En G. Torello e I. Wschebor (Eds.), La pantalla letrada. Estudios interdisciplinarios sobre cine y audiovisual latinoamericano (pp. 89-99). Montevideo: Espacio Interdisciplinario, Universidad de la República.

Lagarde, M. (2011). Los cautiverios de las mujeres. Madresposas, monjas, putas y locas. Madrid: Horas y Horas.

Marchesi, A. (2009). Una parte del pueblo uruguayo feliz, contento, alegre. En C. Demasi, A. Marchesi, V. MARKARIAN, Á. Rico y J. Yaffé, La dictadura cívico-militar: Uruguay 1973-1985, (pp. 323-398). Montevideo: Ediciones de la Banda Oriental.

SARAchu, G. (2012) Prácticas integrales: fundamentos, recorridos y experiencias participativas desde la extensión universitaria. En A. L. Cortegoso, G. Sarachu y K. Pereyra (Orgs.), Prácticas académicas integrales en el Cono Sur, (pp. 13-28). Montevideo: CSEAM, Universidad de la República.

Schwarzstein, D. (2001). Una introducción al uso de la historia oral en las aulas. Buenos Aires: Fondo de Cultura Económica.

Secco, L. (2018). Proyecto Uruguay. Ejemplo del uso del documental en dictadura a partir de la serie para televisión de Televisión Educativa. En G. Torello (Ed.), Uruguay se filma. Prácticas documentales (1920-1990), (pp. 65-86). Montevideo: Irrupciones.

Silveira, G. (2015). Cine e identidad en dictadura. Una aproximación al público de la Cinemateca Uruguaya. 33 cines, tercera época, (3), 1-13.

Silveira, G. (2019). Cultura y cinefilia. Historia del público de la Cinemateca Uruguaya. Montevideo: Cinemateca Uruguaya. 
Universidad de la República, Consejo Directivo Central (2009, octubre 27). Para la renovación de la enseñanza y la curricularización de la extensión y las actividades en el medio. (Resolución n. ${ }^{\circ}$ 5). Recuperado de http://www.expe.edu.uy/expe/resoluci. nsf/4e1fd2c2a317193a03256dccoo3b9o2f/f20o247a7f556d23032576550069eo6o. 